\title{
Inequality and Growth: \\ The Dual Role of Human Capital in Development
}

\author{
Theo Eicher \\ University of Washington \\ Cecilia García-Peñalosa * \\ GREQAM
}

November 1999

\begin{abstract}
This paper examines how the accumulation of human capital determines both a country's growth rate and income inequality. In contrast to previous work, we do not rely on credit market imperfections or political economy arguments. The insight of this model is that inequality is determined by the relative strength of the forces increasing the supply of skills -education- and those increasing the demand for skills -technical change-. We endogenize productivity differentials between skilled and unskilled labor by postulating that they exhibit different degrees of complementarity with new technologies. Our results identify parameters that are central to the evolution of inequality during the development process. We characterise development thresholds when countries switch endogenously from pure learning to directed $\mathrm{R} \& \mathrm{D}$, and we show that biased technical change can generate multiple equilibria that are consistent with the cross country data on inequality and skill premia.
\end{abstract}

Key words: human capital, wage inequality, biased technical change, threshold externalities.

JEL Classification: J31, O40.

Acknowledgements: We are grateful to Philippe Michel, Federico Varese and Jean Pierre Vidal. Cecilia García-Peñalosa gratefully acknowledges the funding received from the European Commission TSER programme through grant SOE2-CT98-3073 (GRIT). Theo Eicher thanks the von Humboldt foundation for generous financial support and Nuffield College and Tübingen University for their hospitality.

\footnotetext{
* Corresponding author. GREQAM, Centre de la Vieille Charité, Marseille 13002, France. Email: penalosa@ehess.cnrs-mrs.fr.
} 


\section{$1 \quad$ Introduction}

The relationship between equity and growth is of fundamental interest not only to economists, but also to policy-makers. Despite the fact that the empirical literature on the subject dates back to Kuznets (1955), no definitive stylized facts have emerged that show how inequality and growth interact during the development process. ${ }^{1}$ This lack of a clear relation between inequality and growth may be partly due to the dual role of human capital in development. While higher rates of growth are associated with greater levels of human capital, the empirical literature suggests that the relationship between human capital and inequality is ambiguous since countries with significantly different levels of human capital exhibit similar returns to education. ${ }^{2}$

In an attempt to analyze the relationship between human capital and inequality, Tinbergen (1975) suggested that inequality was ultimately determined by the opposing effects that technology (skilled labor demand) and education (skilled labor supply) exerted on the relative wage. He stipulated that the relationship between growth and inequality was determined by the "race between technological development and education" (1975 p. 97). Tinbergen's statement has not been formalized and the task of this paper is to model both effects explicitly to shed light on the remarkably diverse empirical relationship between human capital and inequality.

Our analysis utilizes the insights of the New Growth Theory, which emphasizes the endogeneity of technical change and human capital. We show that explicit modeling of endogenous human capital and technology suggests that the relationship between growth and inequality is indeed complex due to the offsetting supply and demand effects. The direct effect of greater supplies of human capital is to lower the skill premium and inequality. Indirectly, however, more human capital also generates more innovations, which in turn increase the demand for skilled workers to absorb new technologies into production. As a result, the model predicts a non-monotonic relationship between educational attainment and inequality, which may explain why empirical cross-country

\footnotetext{
${ }^{1}$ Cross-country evidence on the effect of growth on inequality and on that of inequality on growth is inconclusive (see Anand and Kanbur, 1993a, Deininger and Squire, 1998, and Forbes, 1999), while historical and recent time series shows a diversity of experiences (Williamson 1991, 1999, and Gottschalk and Smeeding, 1997). For a review see, Aghion, Caroli and García-Peñalosa, (1999).

${ }^{2}$ See, for example, Acemoglu, (1999) and Chiu (1998).
} 
analyses of the determinants of income inequality across countries tend to find that school enrollment rates have little explanatory power. ${ }^{3}$

The model has three essential features. First, we explicitly introduce costs and externalities in education, and examine how both relate to learning-by-doing and $\mathrm{R} \& \mathrm{D}$ intensity. ${ }^{4}$ Second, we endogenize the determinants of the skill-bias of labor demand: the complementarity between technology and skilled and unskilled labor. Essentially we provide structure to the Nelson and Phelp (1966) hypothesis that education provides more than an increase in the efficiency units of labor supplied by workers. Third, we differentiate between deliberate $R \& D$ and serendipitous learning by doing. $R \& D$ is the more costly, but also potentially the more productive means of innovation. In addition, deliberate $\mathrm{R} \& \mathrm{D}$ is assumed to require an adequate number of researchers, otherwise the research output is insufficient to justify the cost of a separate $R \& D$ sector. As a result, the model determines endogenously which countries rely only on learning or also on R\&D in order to provide a possible rational for the threshold effects that are abound in the development literature.

The results derived in the paper attract attention to parameters that are central to the supply and demand of human capital, but which have been absent from previous theoretical and empirical analyses of the inequality and growth relationship. We find that either the size of the externality, or the elasticity of substitution between skilled and unskilled in production determine the pattern of inequality during the process of development. Countries that cannot realize large externalities in the education process are likely to exhibit a lower skill level, and high inequality, as R\&D is costly, unrewarding, and difficult to implement. A low elasticity of substitution between skilled and unskilled labor (because of labor laws or the type of products produced, for example) implies that the relative wage declines as growth and human capital accumulation accelerates. This occurs because the lack of substitution between the two types of labor renders wages particularly responsive to changes in the supply. Intermediate ranges for either the elasticity of substitution or the externality in education may generate multiple equilibria

\footnotetext{
${ }^{3}$ See Bourguignon and Morrisson (1998 table 3) and Breen and García-Peñalosa (1999).

${ }^{4}$ Rather than focusing on parental effects in education (as Galor and Tsiddon 1996, for example), we are concerned with group externalities in education, following the growing literature on external effects within
} 
with either falling or U-shaped wage inequality as human capital and growth increase. Such behavior could help explain the findings of Anand and Kanbur (1993a) that when estimating the relationship between income inequality and development for a crosssection of countries, the data is best approximated by a U-shaped function.

These implications mirror Tinbergen's (1975) hypothesis that the pattern of relative wages along the development path depends on the strength of the demand for skills exerted by technology and the supply of skills generated by education. Our model emphasizes that whether a country experiences rising or falling inequality as the growth rate increases depends on the externality (social returns) in education, the evolution of the direct cost of education, and the elasticity of substitution in production between skilled and unskilled. In addition, we highlight that the strength of the demand and supply forces also depend on the research productivity and the learning content of production goods, which in turn also influence the relationship between growth and inequality. Neither of these variables has thus far been included in the regressions that attempt to untangle the relationship between inequality and growth across or within countries. Since it is likely that the use of advanced technologies lowers the elasticity of substitution of skilled and unskilled in production, the product mix of a country should also enter as an important determinant into growth and inequality regressions.

Our second result is the endogenous emergence of poverty traps. Azariadis and Drazen (1990) examined the implications of threshold effects on the supply side, while Acemoglu (1996) and Redding (1996) introduced poverty traps due to coordination problem between firms and workers. ${ }^{5}$ Our model provides another possible mechanism for poverty traps: the interdependence of the supply and demand for skilled labor, when technical change is skill-biased. Essentially, a greater supply of skilled labor increases the rate of technical change, which in turn increases the relative demand for skilled workers to absorb the new technology into production. The extra demand provides additional incentives to invest in education, hence the economy finds itself in a virtuous cycle. Alternatively a low-growth trap is feasible, where a low relative wage, a small stock of human capital, and slow growth generate few incentives to invest in skills.

schools and the role of "social capital" in human capital accumulation. See Tamura (1991) and Benabou (1996a, 1996b) for models with externalities at the school level, and Borjas (1995) for related evidence. 
The existence of multiple equilibria convergence clubs is consistent with recent empirical findings (see, for example, Quah 1996). In our model development thresholds are endogenously generated, since the move from learning to $R \& D$ occurs only when the income generated from R\&D justifies the factor payments to the sector. Intuitively, it is not sensible to conduct $R \& D$ if the resource costs outweigh the benefits from the R\&D. With few skilled workers, the research output is small, the costs of implementing new technology are high, and the benefits to the final good production are reduced. In addition, the benefits to $R \& D$ are even further depressed as slow rates of technical change can easily be handled by unskilled labor.

The previous literature on inequality and growth falls into several different classes. The early literature stipulates imperfect mobility between distinct sectors (from agriculture to industry), which affects the distribution of labor incomes. ${ }^{6}$ Recent approaches are based on capital market imperfections, where credit imperfections constrain the amount of human or physical capital to be accumulated and thus affect inequality. ${ }^{7}$ We do not rely on credit constraints but on endogenous productivity differentials and on threshold externalities in research to generate inequality along the development path. Instead of credit markets or unequal ex ante distributions of human capital, it is the technology-driven labor demand that is central to explaining inequality and development in our model. An alternative, political economy approach relies on socio political (in)stability and redistribution to generate inequality that is consistent with the data. ${ }^{8}$ In contrast to the above models our focus follows the empirical analyses of inequality that track the evolution of the differences between skilled and unskilled wages, as exemplified by the work of Williamson (1991, 1999). Galor and Tsiddon (1996) also examine the effects of technological change on human capital accumulation and the skill premium, however, their inequality pattern within and across countries is driven by the initial distribution of human capital.

The structure of the paper is as follows. Section 2 presents the model, specifying the relative demand for labor, the supply of skills, and technological change. Section 3

\footnotetext{
${ }^{5}$ See Azariadis (1996) for a survey on the literature on poverty traps.

${ }^{6}$ See Kuznets (1953), Harris and Todaro (1970).

${ }^{7}$ see Galor and Zeira (1993), Banerjee and Newman (1993), Chiu (1998).
} 
describes the general equilibrium and stationary states, and section 4 the possible patterns of inequality and growth and how they depend on parameter values. We then discuss our results in the light of empirical evidence, and examine possible policy options. Section 6 concludes.

\section{Production structure}

\subsection{Final and Intermediate Goods}

A competitive final goods sector produces one homogeneous output using human capital and a variety of intermediate inputs. The basic production structure of the final good is based on Romer (1990), with output being produced according to

$$
Y_{t}=\sum_{i=1}^{D_{t}} n(i)_{t}^{1-\delta} H_{t}^{\delta},
$$

where $D$ represents the number of different intermediate goods used in production, $n(i)$ is the quantity of the ith intermediate good employed, and $H$ is the skill-adjusted stock of labor in the economy. Technological change takes the form of an expansion of the number of different intermediate goods available.

The intermediate goods sector is competitive, and each intermediate good requires one unit of capital, $k$, to transform a new technology into a new intermediate good. Profit maximization in the intermediate goods sector implies the usual symmetric use of inputs $n(i)_{t}=n_{t}$, which allows us to rewrite (1) as ${ }^{9}$

$$
Y_{t}=D_{t} n_{t}^{1-\delta} H_{t}^{\delta} .
$$

Our aim is to provide additional structure to the absorption process that differentiates skilled and unskilled labor. The two types of labor differ not only in terms of productivities, but also in their technological capabilities. Previous growth models stipulate exogenous productivity differentials between skilled and unskilled workers; we endogenize these differentials. We posit that technology is not equally complementary with skilled and unskilled labor, but that skilled workers possess a greater capacity to absorb new technologies and to better handle increased technological change. Exactly how complementary technology is with the respective types of labor will be a function of the rate of technological change itself. That is, the greater the speed of technological

\footnotetext{
${ }^{8}$ See Bertola (1993), Alesina and Rodrik (1994), Person and Tabelini (1994) and Alesina and Perotti
} (1995). 
change, the relatively more productive skilled labor becomes, compared to unskilled labor. To generate such endogenous relative productivities, we assume that the skilladjusted stock of labor can be disaggregated according to the following CES function:

$$
H_{t}=\left(\frac{D_{t-1}}{D_{t}} U_{t}^{-\alpha}+\left(S_{t}^{P}\right)^{-\alpha}\right)^{-1 / \alpha},
$$

where $S_{t}^{P}$ denotes skilled labor employed in production and $U_{t}$ unskilled labor. We will restrict the degree of substitutability between the two types of labor, and assume that $0>\alpha>-1$. The resulting elasticity of substitution, $\phi=1 /(1+\alpha)$, then takes values in the interval $(1, \infty)$, implying that skilled and unskilled labor in production are imperfect substitutes.

Equation (3) also implies that the relative shares of skilled and unskilled in the total effective labor force (or in the total product) are a function of the rate of technological change. This assumption is akin to the Nelson and Phelps (1966) argument that greater skills allow for faster adoption of technology. It also receives strong support from empirical studies, such as Bartel and Lichtenberg (1987), who show that the relative demand for skilled workers declines in the age of plant and equipment and that technology enters labor demand non-neutrally.

Alternatively, one could interpret the disaggregation as one where workers without skills can only use older technologies, as only skilled labor is capable of working with cutting edge technologies in production. Hence, the production structure incorporates the notion that not only the absolute, but also the relative productivities of skilled to unskilled labor change with the level of development, or with the rate of progress observed in an economy.

From (1) and (3) the labor demand can be derived as a function of the rate of technological change and the relative wage of skilled to unskilled labor, $\omega_{t}$ :

$$
\omega_{t} \equiv \frac{w_{t}^{S}}{w_{t}^{U}}=\left(\frac{U_{t}}{S_{t}^{P}}\right)^{1+\alpha} \frac{D_{t}}{D_{t-1}} .
$$

Equation (4) shows that, on the production side, the relative wage is determined by two standard factors: relative factor supplies and relative productivity. The later is, however,

\footnotetext{
${ }^{9}$ See the appendix for the complete intermediate firm problem.
} 
determined by technological change. An increase in the relative supply of skilled workers lowers the relative wage, while an increase in the rate of technological change raises it . Depending on the strength of each factor, the effects of an increase in technological change may well outweigh the effects of concurrent increases in the skilled labor force.

\subsection{Factor Supplies}

This section outlines the incentives to invest in education, given the relative returns to skilled and unskilled labor. Agents live for two periods, work only when young and, for simplicity, consume only when old. Let $S_{t}$ denote the total number of skilled workers in the economy, and $U_{t}$ the number of unskilled workers. We normalize the size of the population to unity, which implies the labor constraint

$$
U_{t}+S_{t}=1
$$

Skilled workers can be employed either in production, $S_{t}^{P}$, or in research, $S_{t}^{R}$.When new technologies are introduced, agents must learn to work with these technologies to become skilled labor. Hence, at the start of their working lives, agents have to decide whether to invest in education or to remain unskilled. Agents possess perfect foresight and skills are acquired only through formal education. We assume that agents differ in their abilities to learn, $a$, and that these abilities are distributed uniformly, $a \in[0,1]$.

The cost of education takes the following form, $c_{t} w_{t}^{U} / a$. That is, two components determine the cost of education. First, there is a direct $\operatorname{cost} c_{t} w_{t}^{U}$, due to either tuition or forgone wages during the time spent in education. This cost is proportional to the unskilled wage and therefore increases as the economy grows. In addition, more able individuals can learn faster/better and therefore incur a lower cost, captured by $a$ in the denominator.

We postulate that the direct cost of education is a function of the number of agents being educated, so that $c_{t}=c\left[S_{t}\right]$. More specifically, we assume that it decreases in the number of agents seeking schooling, $c^{\prime}[]<$.0 . This assumption may account for fixed costs in the education process, such as physical structures or the cost of taking teachers to rural areas. Alternatively one could motivate the declining marginal cost of 
education as the result of externalities in the education process. ${ }^{10}$ It has become standard to assume in growth models that a greater aggregate stock of human capital increase the skills acquired from a given educational investment. We reverse this relationship, and argue that a greater stock of human capital makes it less costly to attain a given level of skills. For simplicity, we assume a specific functional form for the education cost, $c\left[S_{t}\right]=\rho S_{t}^{-\sigma}$, which incorporates a clear direct cost, $\rho$, and a measure of the externality, $\sigma \cdot{ }^{11}$

In order to decide whether to invest in skills, agents compare the respective utilities of skilled and unskilled, where $\Omega[$.] is the utility function. To allow for differential taxation of skilled and unskilled, we impose an income tax of $\tau$ only on skilled wages. Let the return on savings be $r$ and the discount factor $b$. Then, the utility of a skilled worker born at time $t$ can be written as a function of her wage income net of the education $\operatorname{cost}^{12}$

$$
\Omega_{t}^{S}\left[\left((1-\tau) w_{t}^{S}-\frac{\rho S_{t}^{-\sigma} w_{t}^{U}}{a}\right) \frac{\left(1+r_{t}\right)}{b}\right] .
$$

Agents choose to invest in skills if the utility in (6) exceeds that of remaining unskilled, $\Omega_{t}^{U}\left[w_{t}^{U}\left(1+r_{t}\right) / b\right]$. In equilibrium, the instantaneous utilities of skilled and unskilled must be equal, which immediately implies a level of ability that renders agents indifferent between investing in education or working as unskilled: $a_{t}^{*}=\rho S_{t}^{-\sigma}\left(\omega_{t}(1-\tau)-1\right)^{-1}$. The labor constraint (5) together with the uniform ability distribution, or $S_{t}=1-a_{t}^{*}$, and utility equalization allow us to express the relative wage as a function of the number of skilled workers,

$$
\omega_{t}=\left(1+\frac{\rho S_{t}^{-\sigma}}{1-S_{t}}\right)(1-\tau)^{-1} .
$$

\footnotetext{
${ }^{10}$ See Coleman (1990) for a discussion of social capital and its impact on educational attainment, Borjas (1995) for evidence of externalities at the school level, and Psacharopulous and Woodhall (1985) for evidence that initial years of schooling are usually the most cost effective and productive in terms of educational expenditures.

${ }^{11}$ As we will show in the appendix, $1+\alpha \geq \sigma$ is required for stability.

${ }^{12}$ See Appendix 1 for a description of the capital market equilibrium
} 
The above inverse labor supply equation gives the relative wage needed to induce $S$ workers to invest in skills. The relative wage first declines and then rises in the stock of skilled labor. The initial decline reflects the decrease in the cost of education as more agents opt for education. Subsequently, the rising opportunity and effort costs dominate to force an increase in the relative wage to elicit a greater supply of skilled labor. The relative wage equation thus highlights the effects of increasing returns to education at different stages of development. For low levels of development, the abundance of unskilled labor keeps the opportunity cost low, which combines with high returns to education and large spillovers to provide strong incentives to invest in education. As the stock of skilled workers rise, so do the opportunity and effort costs, which eventually outweigh the effects of the education externality.

Expressed in the wage-labor space, $(\omega, S)$, the labor supply function, (7), shifts upwards as the direct cost of education increases, $\rho$, and its minimum occurs at $\tilde{S}_{t}=\sigma /(1+\sigma)$. Hence an increase in the externality moves the minimum to the right, implying that stronger externalities in education prolong the decline in relative wages. The differential tax rate that is levied on skilled workers shifts the curve up, as it increases the relative wage to induce an equal amount of skilled to seek education. These findings pertaining to the externality, the tax, and the direct cost of education are summarized in proposition 1.

\section{Proposition 1 "Labor Supply"}

Externalities in education, $\sigma$, generate a $U$-shaped relationship between the relative wage and the supply of skilled labor. The greater the externality, the more prolonged the initial decline of the relative wage. Increases in the direct cost of education, $\rho$, or in the differential tax on skilled labor, $\tau$, require higher relative wages for each level of skilled labor supply.

\subsection{Technological change}

Ever-new technological blue-prints are employed in the intermediate goods sector, together with a unit of capital, to produce a new type of intermediate good that is then used by the final-good sector. There are two possible ways of generating new 
technologies. First, via learning by doing (henceforth LBD); second, through deliberate and costly investment in research and development (R\&D).

Learning by doing takes place as skilled workers serendipitously discover better technologies during the production processes. We assume that it takes the form

$$
\left.\frac{D_{t}}{D_{t-1}}\right|_{L B D}=1+\gamma S_{t-1}, \quad \gamma>0 .
$$

The exclusive reliance on learning by doing is thought to be limited to the early stages of development when skilled labor is perhaps too scarce to allow for a dedicated research and development activity. In our model, a country switches endogenously to deliberate $R \& D$, once it has attained a sufficient number of skilled labor. To simplify the research sector, we follow Shell (1967) and Grossman and Helpman (1991, section 2.4) and assume that research is financed by a public entity that raises revenues through tax collections, $\tau \cdot{ }^{13}$ When a number of researchers $S_{t}^{R}$ are employed, the economy produces technological blue-prints according to

$$
\left.\frac{D_{t}}{D_{t-1}}\right|_{R \& D}=\left(1+\gamma S_{t-1}\right) \beta S_{t-1}^{R}, \quad \beta>1 .
$$

In equation (9) we posit that technical change is an amalgam of learning by doing and research effort. Hence, learning does not cease when R\&D is undertaken, but it continues to contribute to the technology output.

More importantly, however, is the assumption that a sufficiently large number of skilled researchers, $S_{t}^{R}$, is required to generate a rate of technological change that exceeds pure learning by doing. Consistent with the motivation for (8), equation (9) reflects that $R \& D$ is not necessarily sensible for all types of economies. For low levels of skilled labor, R\&D will not be profitable - not just in terms of final output but also in terms of the generated rate of technical change. Only after a country is sufficiently developed in terms of its supply and demand for skilled labor, will deliberate $R \& D$ be done. When R\&D becomes economically feasible, the dedicated research effort generates

\footnotetext{
${ }^{13}$ Any (more complex) means of R\&D financing is feasible as long as it retains the proportionality between the total stock of skilled labor, and the shares of labor allocated in production and research. Otherwise balanced growth is not feasible.
} 
a crucial advantage over the pure learning by doing: it leads to greater advances in knowledge.

Having specified the mechanics of technical change, we can write the labor constraint for skilled workers when $\mathrm{R} \& \mathrm{D}$ is undertaken as $S_{t}^{P}+S_{t}^{R}=S_{t}$. If no $\mathrm{R} \& \mathrm{D}$ is done, all skilled labor work in production.

We assume that when the government undertakes $R \& D$, the blue-prints are put in the public domain and can be used at no cost. Research is financed by tax revenues, and the fiscal budget is always balanced. The budget constraint is then $\tau w_{t}^{S} S_{t}=w_{t}^{S} S_{t}^{R}$. Any excess revenues at the end of the period are classified as fiscal waste.

Given the budget constraint and the skilled labor market constraint, we find that the number of skilled workers that contribute to $R \& D$ and to production is given by

$$
\begin{aligned}
& S_{t}^{R}=\tau S_{t} \\
& S_{t}^{P}=(1-\tau) S_{t}
\end{aligned}
$$

We can now utilize the equations for technological change under LBD and R\&D, (8) and (9), and substitute for the division of skilled labor, (10) and (11), into equation (4) to derive the inverse relative labor demands under the two regimes. That is,

$$
\begin{aligned}
& \left.\omega_{t}\right|_{L B D}=\left(1+\gamma S_{t-1}\right)\left(\frac{1-S_{t}}{S_{t}}\right)^{1+\alpha}, \\
& \left.\omega_{t}\right|_{R \& D}=\beta \tau \frac{\left(1+\gamma S_{t-1}\right) S_{t-1}}{(1-\tau)^{1+\alpha}}\left(\frac{1-S_{t}}{S_{t}}\right)^{1+\alpha},
\end{aligned}
$$

Equations (12) and (13) imply that the demand for skilled labor is a lagged function of its supply, as the relative wage is decreasing in the current stock of skilled labor but increasing in the last period's stock. The reason for this is that a greater proportion of skilled labor in period $t-1$ results in faster technological change, which means that the productivity of skilled labor is growing more rapidly than that of unskilled labor. This raises the demand for skills at $t$, and therefore the wage ratio for any given supply.

\section{General Equilibrium and Stationary States}

General equilibrium in the goods and factor markets is attained by equating the labor supply, given in equation (7), to the labor demand, (12) and (13), which renders two differential equations in $S_{t}$ and $S_{t-1}$. The exact expressions for these equations are given in 
the appendix. ${ }^{14}$ In what follows we impose the restriction that $1+\alpha>\sigma$, that is, the education externality is not too strong given the elasticity of substitution between the two types of labor. This ensures that $S_{t}$ is increasing in the previous period's stock of skills.

The equilibrium is best expressed in $(\omega, S)$ space, which relates relative wages and income inequality to the level of development and economic growth. Consider the steady state behavior of the model. In steady state, $S_{t-1}=S_{t}=S$, and equilibrium is given by the intersection of the labor supply function with the steady state labor demand. This yields $S^{*}$ as a function of the parameters of the model, as shown in the appendix. Once the equilibrium stock of skilled labor is obtained, it uniquely determines the degree of wage inequality and the rate of growth of the economy. Relative wages are given by the supply of labor function. To obtain the rate of output growth, note that in steady state all inputs except the number of intermediate goods available are constant. The steady state growth rate is then given by

$$
\frac{Y_{t}-Y_{t-1}}{Y_{t}}=\frac{D_{t}-D_{t-1}}{D_{t}}=\left\{\begin{array}{cc}
\gamma S^{*} & \text { LBD } \\
\left(1+\gamma S^{*}\right) \beta \tau S^{*}-1 & \text { R \& D }
\end{array}\right.
$$

and hence uniquely determined by the level of human capital in the economy.

Imposing the steady state condition, $S_{t-1}=S_{t}=S$, allows us to depict the relative labor demand functions in the $(\omega, S)$ space. Labor demand is downward sloping if LBD is the source of technical change. ${ }^{15}$ However, when deliberate R\&D effort is used in the economy, the labor demand becomes log-concave and intersects the horizontal axis at $S=$ 0 and $S=1$. The demand for labor under R\&D is initially upward sloping since more researchers raise the marginal product of skilled labor in output and allow for more $\mathrm{R} \& \mathrm{D}$, which again improves the productivity of skilled labor in production. Demand cannot be upward sloping throughout, since unskilled labor eventually becomes sufficiently scarce to exert downward pressure on the relative wage.

R\&D labor demand reaches its maximum at a level of the skilled labor supply $\hat{S}=\left((1-\alpha)-1 / \gamma+\left(((1-\alpha)-1 / \gamma)^{2}-8 \alpha / \gamma\right)^{1 / 2}\right) / 4$. This implies that increased

\footnotetext{
${ }^{14}$ Stability and existence are also proven in the appendix.
} 
productivity in learning, $\gamma$, prolongs the upward sloping section of the relative demand curve, since more skilled workers generate sufficiently greater technological change to justify prolonged relative wage increases. A higher elasticity of substitution between skilled and unskilled (that is, a lower $\alpha$ ), has the same effect, as it slows down the rate at which the scarcity of unskilled labor reduces the relative wage.

The intersection between the LBD and R\&D labor demand curves implies a development threshold. No R\&D will be undertaken until the productivity of skilled workers in the R\&D regime starts to exceed that of the LBD regime. The critical level of skilled labor necessary to equalize the productivities is $\tilde{S}=(1-\tau)^{1+a} / \beta \tau$. This shows that the development threshold decreases in the productivity of researchers and in the tax rate. ${ }^{16}$ An economy with more productive researchers thus finds deliberate $R \& D$ rewarding for lower levels of skilled labor. Equivalently, an economy that diverts a greater share of income to finance research allocates a relatively larger share of its skilled labor force to the $R \& D$ sector, which renders $R \& D$ attractive at lower levels of development. Hence the aggregate labor demand function is a titled $\mathrm{S}$ shape as seen in figure 1.

\section{Proposition 2 "Labor Demand"}

Research requires an adequate quantity of sufficiently productive skilled workers, else the country must rely on pure learning by doing to develop new technologies. Both learning and research are skill intensive. Relative demand for skilled labor increases in the learning productivity, $\gamma$, in the funding for research, $\tau$, and in the productivity of skilled workers in research, $\beta$.

Labor demand is downward sloping and log concave under learning and $R \& D$, respectively. Greater learning productivity, $\gamma$, or higher elasticity of substitution

\footnotetext{
${ }^{15}$ From (12), $\partial \omega / \partial S<0$ for $S=0$, and $\partial \omega / \partial S<0$ for all $S \in[0,1]$ if $\gamma<4(1+\alpha) / \alpha^{2}$. The limit on the learning productivity is necessary so that firms do not employ workers only because of their contribution to learning by doing rather than production.

${ }_{16}$ Alternatively, the government could choose to start doing research when the stock of skilled labor is high enough to make the output of the $\mathrm{R} \& \mathrm{D}$ sector is equal to that obtained under learning-by-doing. From equations (8) and (9) this occurs when $S$ is $\bar{S}=1 / \beta \tau>\tilde{S}$. If this were the threshold at which R\&D starts, none of the results in Propositions 2 and 3 would change, the only difference being that there would be a discontinuity in the steady state demand function.
} 
between skilled and unskilled, $\phi$, prolong the upward sloping segment of the relative demand curve under $R \& D$.

The switch from learning to deliberate $R \& D$ occurs earlier if the share of income devoted to financing research, $\tau$, and the productivity of researchers, $\beta$, increases.

Figure 1 shows three distinct phases of development. The examination of each phase establishes intuition for the tilted S shape of the economy wide labor demand. In the early stages of development, the stock of skilled is small and learning by doing is the only form of technical change. At this stage of development, unskilled workers are relatively productive in the final goods sector, compared to skilled labor and the positive effects of technological change are weak. Thus the labor supply effect dominates and more skilled labor is associated with lower relative wages.

Economies that are more technologically advanced and that possess a sufficiently large stock of skilled labor (phase two) surpass the development threshold and switch endogenously to a dedicated R\&D sector. At this stage of development, the active R\&D sector produces significantly greater technical change causing the technology driven demand for skilled labor to outweigh the labor supply effect. Hence, due to the strong technology-skill complementarity in production, the relative wage initially rises together with the stock of skilled labor.

Countries in advanced stages of development (phase three) find that the increasing scarcity of unskilled labor exerts ever-stronger downward pressure on the relative wage to mute the effects of skill biased technical change. To rule out an equilibrium where all workers in the economy invest in skills, the relative wage declines to zero as the number of skilled workers approaches unity. Once labor supply is added, these three stages of development will be associated with three possible equilibria. ${ }^{17}$

\section{Human Capital, Inequality and Growth}

\subsection{Possible Equilibria and Wage Profiles}

It is most convenient to examine the possible equilibria and wage time profiles in figures 2a-2e. These figures depict the steady state labor demand and labor supply functions, hence the intersections between the two represent possible steady state equilibria. Note, however, that the economy is always on the labor supply function, as it 
represents the wage required at time $t$ given the supply of skills in that period. Hence, the development process will consist of movements along this curve until a steady state equilibrium is reached.

Four classes of equilibria can be identified. The first two categories consist of equilibria 2a (2c), where greater levels of human capital and growth are associated with monotonic increases (decreases) in inequality. Two conditions combine to allow declining relative wages to be associated with equilibria that feature successively higher growth rates. The first condition is a prolonged decline of the labor supply function; the second, an early decline of the relative demand for skilled labor under the R\&D regime. A strong externality in education allows for the former, while a low degree of substitution and low learning productivity accomplishes the latter. The two conditions that combine to generate increasing relative wages are exactly opposite to those necessary for the previous case. A shortened decline of the labor supply function (due to a weak externality in education) and a late decline of the relative demand for skilled labor under the R\&D regime (because of a high degree of substitution and great learning productivity) suffice.

A third pattern of inequality is shown in Fig $2 b$. Here the relationship between inequality and growth reverses as the endogenous stock of skilled labor increases. A low growth equilibrium is associated with low equality, a medium growth equilibrium shows increased equality, but the high growth equilibrium finally exhibits high levels of inequality. This situation is observed for intermediate values of the externality in education, the elasticity of substitution, and the extent of learning-by-doing.

Finally the fourth class of equilibria is shown in $2 \mathrm{~d}$ and $2 \mathrm{e}$. In both cases the economy exhibits a unique equilibrium with (without) R\&D. Each equilibrium is attained independently of the initial conditions. If $\mathrm{R} \& \mathrm{D}$ is conducted (2d), the country moves toward the unique stable equilibrium by skipping the pure learning stage in its entirety. If instead the economy converges to the pure LBD equilibrium, R\&D is never performed, no matter how great the initial level of skilled labor may have been. The existence of unique equilibria depends on the direct cost of education, $\rho$, the externality in education, $\sigma$, (decreases in both parameters shift the labor supply function down to rule out the $\mathrm{R} \& \mathrm{D}$ equilibrium), and on the productivity in research, $\beta$, (which not only shifts the

17 In the case of multiple equilibria, Appendix 2 proves that only the odd numbered equilibria are stable. 
labor demand, but also reduces the development threshold, $\tilde{S}$, and renders $\mathrm{R} \& \mathrm{D}$ attractive at lower levels of human capital). We can summarize these findings and state in conjunction with appendix 2:

\section{Proposition 3 "Inequality and Growth"}

The economy exhibits at most three equilibria.

a) Sufficiently low (high) costs of education coupled with strong (weak) externalities in education and high (low) research productivities generate unique, stable high growth (poverty trap) equilibria.

b) Sufficiently strong (weak) externalities in education and low (high) degrees of substitution between skilled and unskilled in production generate multiple equilibria that exhibit monotonically decreasing (increasing) inequality.

c) Intermediate values for the education externality and for the elasticity of substitution in production imply initially declining inequality along the development path, but eventually rising inequality as growth and human capital accumulation increase sufficiently.

\subsection{Significance of the Results}

Research productivity and the direct cost of education are crucial for determining not only the character of an equilibrium (high-growth or poverty-trap) but also whether multiple equilibria can exist. A country with low costs of education and high R\&D sector productivity may skip the pure LBD stage in its entirety and move to a unique R\&D equilibrium, independent of the initial human capital stock. High direct costs of education, in contrast, and low research productivity make it unlikely for countries to surpass the learning by doing stage. Intermediate ranges of these parameters imply multiple equilibria that occur in triplets of low, medium and high growth.

If multiple equilibria are observed, the externality in education and the elasticity of substitution between skilled and unskilled determine the relation between successively higher growth equilibria and the relative wage. High (low) externalities in education and a low (high) substitutability of skilled and unskilled workers in production generate equilibria where successively higher growth rates are associated with ever-lower (greater) inequality. Multiplicity results in poverty traps, where countries are trapped in a no-R\&D equilibrium, even though a high growth equilibrium would be feasible for the economy's 
parameter values. Only if the initial stock of labor exceeds the level associated with the unstable, middle equilibrium, does the country converge to the stable R\&D equilibrium. If the initial level of skilled labor is not sufficiently high, the country reverts to the development trap in which only learning by doing generates technical change. With multiplicity, history matters dramatically, as initial conditions determine whether the country finds itself with an active research sector or not. It renders development pathdependent, since countries with similar technological parameters may now gravitate to either the low or high growth equilibrium.

Multiplicity emerges as the result of two features of our economy: skilled-biased technical change and the fact that new knowledge is generated by skilled labor. Essentially, a greater supply of skilled workers accelerates technical change, which in turn increases the relative demand for these workers in order to absorb the new technology. Because demand is high, there are enough incentives to invest in education and the greater stock of skilled labor is supported by equilibrium wages. The economy thus finds itself in a virtuous cycle. Alternatively, the economy can be stuck in a lowgrowth trap, where a low relative wage, caused by the fact that slow technical change implies a small demand for educated labor, generates no incentives for workers to further invest in skills. These features of the model thus formalize Tinbergen's (1975) hypothesis that the pattern of relative wages along the development path depends on the strength of the demand for skills exerted by technology and the supply of skills generated by education.

Unlike in Shell (1967) who modeled the public provision of technology, an increase in publicly funded $\mathrm{R} \& \mathrm{D}$ expenditures does not unambiguously increase economic growth. As in previous models that incorporate productive government spending (e.g., Barro, 1990), the tax in our model has two opposing effects on the growth. Higher taxes affect the provision of new productive technology, but also present additional disincentives to accumulate the crucial resource that drives economic growth: human capital. Because revenues are generated through a tax on skilled wages, a change in the tax rate affects both the supply and the demand for skills. A higher tax rate increases the proportion of educated workers employed in the research sector, thus raising the rate of technical change and shifting upwards the labor demand function (see 
Proposition 2). At the same time, a higher tax reduces the net income of skilled workers. The incentives to invest in skills are diminished and the stock of skilled workers falls, shifting downwards the labor supply (see Proposition 1). Consequently, the total number of researchers, and hence the growth rate, may be greater or smaller than under the lower tax rate. In other words, if research expenditures are financed through a progressive labor income tax, a higher tax rate may reduce $R \& D$ expenditure because of its effect on the supply of researchers.

\section{Conclusion}

There is no clear empirical regularity that describes the evolution of inequality along the development process, either within or across countries. Recent dual economy models have provided a possible explanation. Expanding the original Kuznets argument to allow for intra-sectoral inequality, yields the possibility of inequality patterns different from the traditional inverse-U shaped relationship (see Anand and Kanbur, 1993b, and Fields, 1993). This paper has presented an alternative mechanism based on the dual role of human capital. We have argued that the stock of educated workers in an economy determines both the degree of income inequality and the rate of growth, and that the parameters of the demand for and the supply of labor are crucial determinants of whether inequality increases or decreases as an economy accumulates human capital.

The driving force of the model is a production function where the relative productivity of skilled to unskilled labor changes with the rate of technical change. New technologies are in turn generated by skilled workers, which implies that the relative demand for labor, and hence the skill premium, are not monotonically decreasing in the stock of skills in the economy. When we pair this demand function with a supply of labor function, we find, first, that multiple equilibria are possible, and, second, that as a country accumulates skills inequality may increase, decrease, or follow a U-shaped path. The trajectory followed by a particular country will depend on the direct cost of education, the extent of externalities in the education process, and the elasticity of substitution between skilled and unskilled workers in production.

Of course we make no claim that this is the only, or even the main, determinant of inequality. We simply believe that it is an important part of the story. This is particularly so, given that the "source" of growth seems to have changed substantially. In the words 
of Williamson (1991, p. 90) "the mode of accumulation in the nineteenth century appears to have been much more heavily directed towards conventional capital formation, while the mode of accumulation in the twentieth century seems to have been much more heavily directed towards human capital accumulation". 


\section{APPENDIX 1: The intermediate good sector and capital accumulation}

New technologies for intermediate goods are public goods generated either via learning-by-doing (LBD) or via tax financed R\&D. Differentiating (1) with respect to $n(i)$, the inverse demand function for $\operatorname{good} i$, is $p_{i t}=(1-\delta) n(i)_{t}^{-\delta} H_{t}^{\delta}$. Intermediate goods last for one period, and one unit of capital $k$ is required to produce one unit of intermediate good. Production cost is thus $1+r_{t}$, where $r_{t}$ is the interest rate. Perfect competition implies marginal cost pricing, hence the amount of good $i$ produced at $t$ is

$$
n(i)_{t}^{*}=\left(\frac{1-\delta}{1+r_{t}}\right)^{1 / \delta} H_{t},
$$

which is the same for all types of intermediaries, i.e. $n(i)_{t}^{*}=n_{t}^{*} \forall i$. The aggregate stock of capital is then $K_{t} \equiv n_{t}^{*} D_{t}$.

Since individuals work when young and consume when old, all net labor income is saved, and total labor income is given by $\left(1-S_{t}\right) w_{t}^{u}+\int_{a^{*}}^{1}\left[(1-\tau) w_{t}^{s}-\rho S_{t}^{-\sigma} w_{t}^{u} / a\right] d a$. Integrating, and since $w_{t}^{S}=\omega_{t} w_{t}^{u}$, we can express savings as

$$
Z_{t}=\left(1-S_{t}\right) w_{t}^{u}+(1-\tau)\left(1-a_{t}^{*}\right) \omega_{t} w_{t}^{u}-\rho S_{t}^{-\sigma} \log \frac{1}{a_{t}^{*}} w_{t}^{u}
$$

Substituting for the relative wage from (6) and using the fact that the unskilled wage is given by $w_{t}^{u}=\delta n_{t}^{1-\delta} H_{t}^{\delta+\alpha} U_{t}^{-\alpha-1} D_{t-1}$, we have

$$
Z_{t}=\delta\left(1-S_{t}\right)^{-\alpha-1}\left(\frac{1-\delta}{1+r_{t}}\right)^{(1-\delta) / \delta} H_{t}^{1+\alpha} D_{t-1}\left[1+\rho S_{t}^{-\sigma}\left(\frac{S_{t}}{1-S_{t}}-\log \frac{1}{1-S_{t}}\right)\right]
$$

Capital market equilibrium requires that total savings be equal to the aggregate capital stock, that is $K_{t}=Z_{t}$, which implies

$$
\left(1+r_{t}\right) \frac{\alpha}{1-\alpha}\left(1-S_{t}\right)^{-\alpha-1}\left[1+\rho S_{t}^{-\sigma}\left(\frac{S_{t}}{1-S_{t}}-\log \frac{1}{1-S_{t}}\right)\right]=H_{t}^{-\alpha} \frac{D_{t}}{D_{t-1}}
$$

The right-hand-side of this equation is a function of $S_{t}$ and $S_{t-1}$ (through $H_{t}$ and $D_{t} / D_{t-1}$, respectively). Since $S_{t-1}$ is given and $S_{t}$ is determined by the labor market equilibrium that does not depend on $r_{t}$ (see below), this equation defines the equilibrium 
interest rate at time $t$ as a function of the current and the previous period's supply of skills.

\section{APPENDIX 2: Existence and Dynamic Behavior}

Define $\Psi\left(S_{t}\right) \equiv \frac{1}{1-\tau}\left(1+\frac{\rho}{\left(1-S_{t}\right) S_{t}^{\sigma}}\right)\left(\frac{S_{t}}{1-S_{t}}\right)^{1+\alpha}$

Substituting the inverse supply function into the labor demand functions (12) and (13), we obtain the first order difference equations that govern the dynamics of the stock of skilled labor in the economy for the LBD and R\&D case, respectively:

$$
\begin{aligned}
& 1+\gamma S_{t-1}=\Psi\left(S_{t}\right), \\
& \frac{S_{t-1}}{\tilde{S}}\left(1+\gamma S_{t-1}\right)=\Psi\left(S_{t}\right) .
\end{aligned}
$$

\section{Part I: Dynamics of the equilibria}

Differentiating, we have

$$
\frac{\partial \Psi}{\partial S_{t}}=\frac{\rho(1+\alpha-\sigma)+(1+\alpha)\left(1-S_{t}\right) S_{t}^{\sigma}+\rho(1+\sigma) S_{t}}{(1-\tau)} \frac{S_{t}^{+\alpha-\sigma}}{\left(1-S_{t}\right)^{3+\alpha}} .
$$

Note that $1+\alpha \geq \sigma$ is a necessary and sufficient condition for $\partial \Psi / \partial S_{t}>0$ in the interval $[0,1]$. Since the left-hand sides of both equation (A2.1) and (A2.2) are increasing in $S_{t-1}$, the restriction $1+\alpha \geq \sigma$ implies that $\partial S_{t} / \partial S_{t-1}>0$ both under LBD and R\&D.

In order to examine the dynamics of the model, we depict the right- and left-hand sides of equations (A2.1) and (A2.2) graphically in figure A.1. Under the assumption $1+\alpha \geq \sigma$, the function $\Psi\left(S_{t}\right)$ has the following properties:

(i) $\quad \partial \Psi / \partial S_{t}>0$ in the interval $[0,1]$,

(ii) $\Psi\left(S_{t}\right)$ is first concave and then convex,

(iii) $\Psi\left(S_{t}=0\right)=0$ and $\Psi\left(S_{t}=1\right)=\infty$,

(iv) higher values of $\rho$ and $\sigma$ shift $\Psi\left(S_{t}\right)$ upwards.

During the LBD phase, the left-hand side of equation (A2.1) is a linear function of $S_{t-1}, f\left(S_{t-1}\right) \equiv 1+\gamma S_{t}$. The LBD equilibrium occurs at the value of $S$ for which $f\left(S_{t-1}\right)=$ 
$\Psi\left(S_{t}\right)$. The two functions always cross once (further intersections are ruled out by the assumption that $\gamma$ is not too large, i.e. $\left.\gamma<4(1+\alpha) / \alpha^{2}\right)$. Only if the intersection occurs for a value of $S$ less than $\tilde{S}$ does the learning-by-doing equilibrium exist. In the R\&D phase, the left-hand side of equation (A2.2) is a convex function of $S_{t-1}$, $h\left(S_{t-1}\right) \equiv S_{t-1}\left(1+\gamma S_{t-1}\right) / \tilde{S}$. The functions $h\left(S_{t-1}\right)$ and $\Psi\left(S_{t}\right)$ cross either twice or not at all in the interval $(0,1)$. If these intersections exist, they will only be an equilibrium if they occur for values $S_{t-1}$ greater than $\tilde{S}$.

There can thus exist three possible equilibria: a low-growth trap in the learning by doing phase and a pair of equilibria in the intermediate and advanced development phase. Figure A.1 represents these three possible intersections. It is straight forward to assess the stability of the equilibria, if they exist, from the figure. We can see that the LBD equilibrium will be stable, while in the R\&D phase the first equilibria will be unstable and the second one stable.

\section{Part II: The possibility of multiple equilibria}

Figure A.1 allows us to examine when will the various equilibria exist. A condition for the existence of the LBD equilibrium ( $R \& D$ equilibria) is that the direct cost of education be high (low) enough (see below). A reduction in the cost of education shifts down $\Psi\left(S_{t}\right)$. Hence, for very low $\rho$ the LBD intersection occurs to the right of $\tilde{S}$ and the LBD equilibrium does not exist. A very high cost of education implies that the functions $\Psi\left(S_{t}\right)$ and $h\left(S_{t-1}\right)$ do not intersect, and the R\&D equilibria do not exist. Similarly, a strong education externality (low value of $\sigma$ ) the shifts down $\Psi\left(S_{t}\right)$, implying that a sufficiently weak (strong) externality is required for the LBD equilibrium (R\&D equilibria) to exist. A high research productivity, $\beta$, makes the $h(S)$ function steeper and moves the threshold $\tilde{S}$ to the left. As a result, the intersection $S_{L}^{*}$ occurs for a value of $S$ greater than $\tilde{S}$ and the low-growth equilibria does not exist. A high value of $\beta$ implies that the intersections $S_{M}^{*}$ and $S_{H}^{*}$ occur for a value of $S$ smaller than $\tilde{S}$ and the low-growth equilibria does not exist. 
It is not possible to obtain precise existence conditions for the equilibria from the differential equations governing the behavior of $S_{t}$. However, we can obtain such conditions from the steady state supply and demand functions. By inspection of the demand and supply functions as depicted in figures $2 \mathrm{a}-2 \mathrm{e}$ we can state the following properties:

(a) A necessary condition for existence of multiple equilibria is that the labor demand function has an upward-slopping section. This will occur if the intersection between the two wage demand curves occurs before the maximum of the log concave curve. That is, if $\tilde{S}<\hat{S}$, which implies

$$
\frac{\gamma}{\beta} \frac{(1-\tau)^{1+\alpha}}{\tau}<\frac{(1-\alpha) \gamma-1+\left(((1-\alpha) \gamma-1)^{2}-8 \alpha \gamma\right)^{1 / 2}}{4} \text {. }
$$

(b) The necessary conditions for existence of a learning-by-doing equilibrium are

- the labor supply must lie below the steady state labor demand curve at $S=0$, which for $1+\alpha \geq \sigma$ always holds, and

- the labor supply must lie above the steady state labor demand curve at the point where LBD ceases, $\tilde{S}$. This condition can be expressed as

$$
\rho>(1-\tilde{S}) \tilde{S}^{\sigma}\left((1+\gamma \tilde{S})(1-\tau)\left(\frac{1-\tilde{S}}{\tilde{S}}\right)^{1+\alpha}-1\right) .
$$

(c) The necessary condition for existence of an $R \& D$ equilibrium is that the labor supply function be below the steady state labor demand function at some point in the interval $(\hat{S}, 1)$. A sufficient condition for this is that the supply function be below the demand function at the maximum of the latter. That is,

$$
\rho<(1-\hat{S}) \hat{S}^{\sigma}\left((1+\gamma \hat{S})(1-\tau)\left(\frac{1-\hat{S}}{\hat{S}}\right)^{1+\alpha} \frac{\hat{S}}{\tilde{S}}-1\right) .
$$

These three conditions have intuitive interpretations. Equation (A2.3) says that in order to have multiple equilibria, the difference between the productivity of R\&D and that of learning-by-doing must be large enough relative to the elasticity of substitution between the two types of labor. That is, the behavior of the economy on the two phases must be "different enough". Equations (A2.4) and (A2.5) imply that the direct cost of 
education determines the possible type of equilibria. A LBD (or low-growth) equilibrium exists only if the cost of education is sufficiently high, relative to the externality and the productivities of skilled labor in generating technological change. Similarly an R\&D equilibrium exists only if the direct cost of education is sufficiently low. Intuitively, this means that if education is very cheap no economy will be locked into a low-growth trap, while if it is very expensive, no economy will be able to reach a high-growth equilibrium. Also, a high productivity of researchers $\beta$ (which raises $\tilde{S}$ ) and a strong externality (i.e. a low $\sigma$ ) increase the right-hand side of both equation (A2.4) and (A2.5), making it less likely for a LBD equilibrium and more likely for an R\&D equilibrium to exist.

Figure A.1 


\section{REFERENCES}

Acemoglu, D. 1996. “A Microfoundation for Social Increasing Returns in Human Capital Accumulation”, Quarterly Journal of Economics, pp. 779-804.

Acemoglu, D. 1999. "Patterns of skill premia"

Aghion, P., E. Caroli and C. García-Peñalosa. 1999. "Inequality and Economic Growth: the perspective of the new growth theories", forthcoming Journal of Economic Literature, vol pp.

Alesina A. and R. Perotti. 1995. "Taxation and Redistribution in an Open Economy", European Economic Review; 39(5), May 1995, pp:961-79.

Alesina A. and D. Rodrik. 1994. "Distributive Politics and Economic Growth", Quarterly Journal of Economics; 109(2), May 1994, pp:465-90.

Anand, S. and S.M.R. Kanbur. 1993a. "Inequality and development: A critique", Journal of Development Economics, 41:1, pp. 19-43.

Anand, S. and S.M.R. Kanbur. 1993b. "The Kuznets Process and the InequalityDevelopment Relationship", Journal of Development Economics, 40:1, pp. 25-52.

Azariadis, C. and A. Drazen. 1990. "Threshold externalities in economic development", Quarterly Journal of Economics 105, pp. 501-526.

Azariadis, C. 1996. "The Economics of Poverty Traps Part One: Complete Markets", Journal of Economic Growth, 1:4, pp. 449-86.

Banerjee, A. and A.F. Newman. 1993. "Occupational Choice and the Process of Development", Journal of Political Economy, 101:2, pp. 274-98

Barro, R. 1990. Government Spending in a simple model of Endogenous Growth", Journal of Political Economy, 98, 5, part 2, pp103-126.

Bartel A.P. and F.R. Lichtenberg. 1987. "The Comparative Advantage of Educated Workers in Implementing New Technology", Review of Economics and Statistics; 69(1), pp:1-11.

Benabou, R. 1996a. "Equity and Efficiency in Human Capital Investment: The Local Connection”, Review of Economic Studies, 63:2, pp. 237-64.

Benabou, R. 1996b. "Heterogeneity, Stratification and Growth: Macroeconomic Implications of Community Structure and School Finance", American Economic Review, 86:3, pp. 548-609.

Borjas, G. 1995. "Ethnicity, Neighborhoods, and Human Capital Externalities", American Economic Review, 85:3, pp. 365-90.

Bourguignon, F. and C. Morrisson. 1998. "Inequality and development: the role of dualism, Journal of Development Economics, 57, pp. 233-57.

Breen, R. and C. García-Peñalosa. 1999. "Income Inequality and Macroeconomic Volatility: An Empirical Investigation", mimeo, Nuffield college.

Chiu, W. H. 1998. "Income Inequality, Human Capital and Economic Performance", Economic Journal, 108, pp. 44-59.

Coleman, J. 1990. Foundations of Social Theory. Cambridge: Harvard University Press.

Deininger, K. and Lyn Squire. 1998. "New Ways of Looking at Old Issues: Inequality and Growth", Journal of Development Economics 57, pp. 259-87.

Fields, G.S. 1993: "Inequality in Dual Economy Models", Economic Journal, 103, pp. 1228-35.h

Forbes, K. 1999. “A Reassessment of the Relationship Between Inequality and Growth”. Mimeo, MIT 
Galor O. and D. Tsiddon. 1996. "Income Distribution and Growth: The Kuznets Hypothesis Revisited", Economica; 63(250), Suppl., pp S103-17.

Galor O. and J. Zeira (1993). "Income Distribution and Macroeconomics", Review of Economic Studies; 60(1), pp:35-52.

Gottschalk, P. and T.M. Smeeding. 1997. "Cross-National Comparisons of Earnings and Income Inequality", Journal of Economic Literature, 35:2, pp. 633-87.

Grossman G. and E. Helpman. 1991. Innovation and Growth in a Global Economy, MIT Press.

Harris J.R. and M.P. Todaro. 1970. "Migration, Unemployment and Development", American Economic Review, 60, pp, 126-142

Kuznets, S. 1955. "Economic Growth and Income Inequality", American Economic Review, 45:1, pp, 1-28.

Kuznets, S. 1963. "Quantitative Aspects of the Economic Growth of Nations", Economic Development and Cultural Change, 11:2, pp, 1-80.

Nelson, R. and E. Phelps. 1966. "Investments in Humans, Technological Diffusion, and Economic Growth", American Economic Review, 61:XX, pp. 69-75.

Perotti, R. 1993. "Political Equilibrium, Income Distribution, and Growth"', Review of Economic Studies, 60:4, pp. 755-76.

Persson T. and G. Tabellini. 1994. "Is Inequality Harmful for Growth? Theory and Evidence", American Economic Review, 84, pp:600-21.

Psacharopoulos, G. and M. Woodhall. (1985) Education for Development, Oxford: Oxford University Press

Quah, D. (1996): "Twin Peaks: Growth and Convergence in Models of Distribution Dynamics", Economic Journal. 106, pp. 1045-55.

Redding, S.. 1996. "The Low-Skill, Low-Quality Trap: Strategic Complementarities between Human Capital and R\&D”, Economic Journal, 106(435), pp. 458-70.

Romer, P.M. (1990): "Endogenous Technological Change", Journal of Political Economy 98, pp. S71-102.

Shell, K. 1967. "A Model of Inventive Activity and Capital Accumulation", in K. Shell ed. Essays on the Theory of Optimal Economic Growth. Cambridge: MIT Press.

Tamura, R. 1991. "Income convergence in an endogenous growth model", Journal of Political Economy, 99:X, pp. 522-40.

Tinbergen J. 1995. Income Distribution: Analysis and Policies, Amsterdam: NorthHolland.

Williamson, J.G. 1991. Inequality, Poverty and History, Oxford: Blackwell.

Williamson, J.G. 1999. "Globalization and the labor market: using history to inform policy", in P. Aghion and J.G. Williamson Growth, Inequality and Globalization, Cambridge University Press, Cambridge. 
Figure A.1

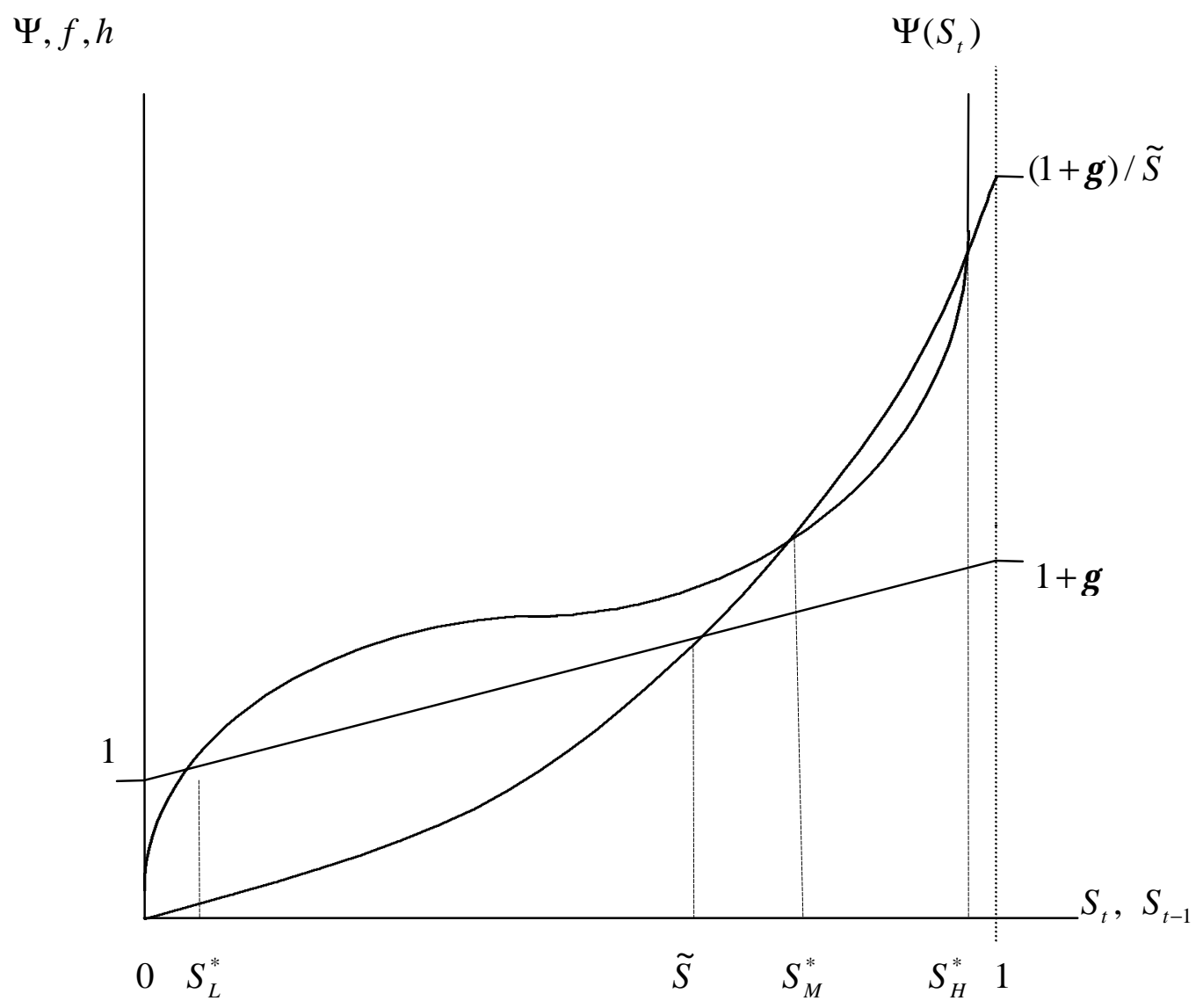


$\omega$

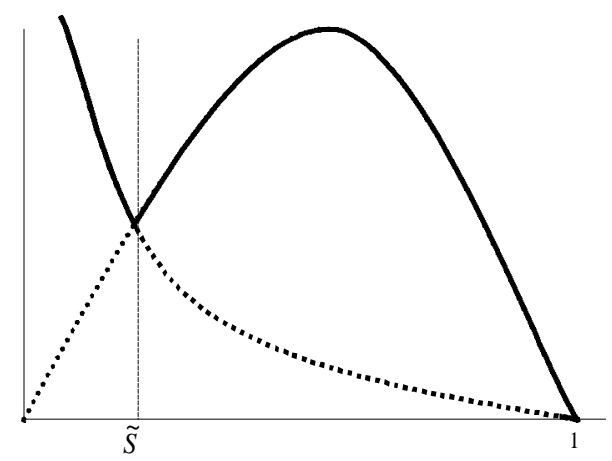

Fig. 1

Labor Demand

$\omega$

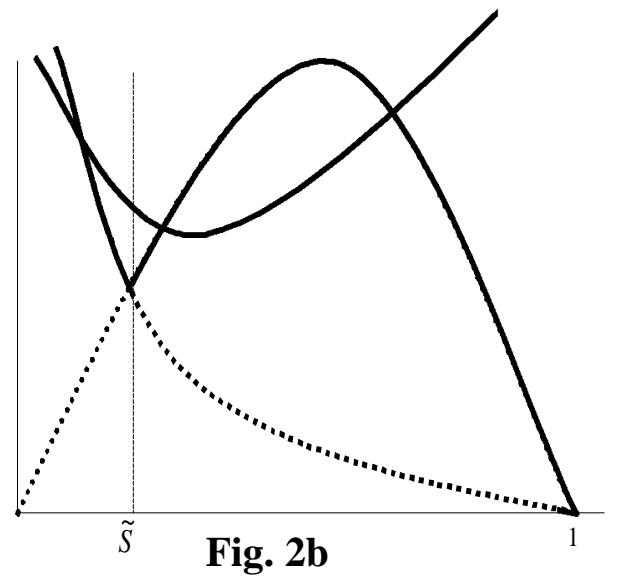

De - and Increasing Inequality

$\omega$

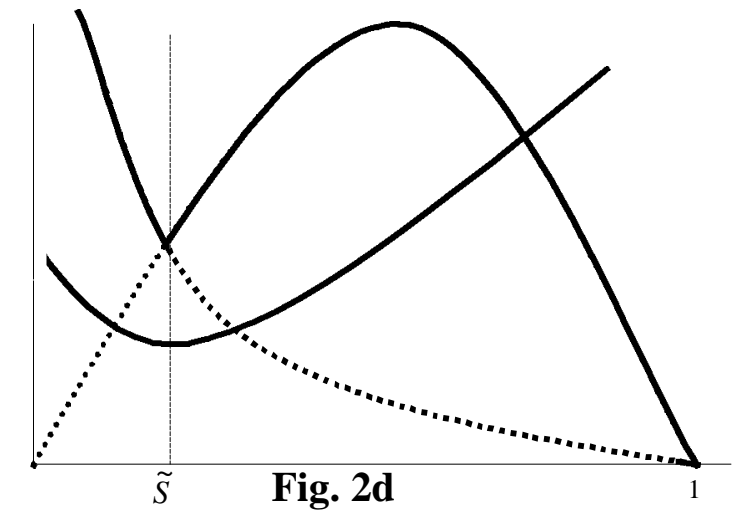

Unique R\&D Equilibrium $\omega$

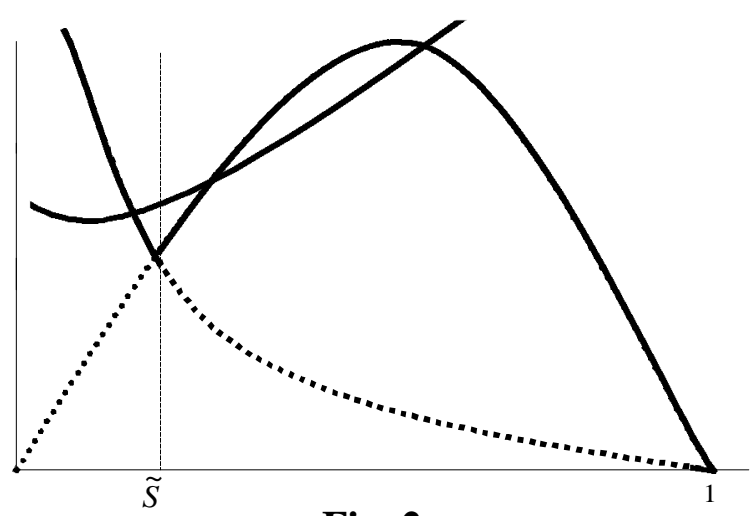

Fig. 2a

Rising Inequality

$\omega$

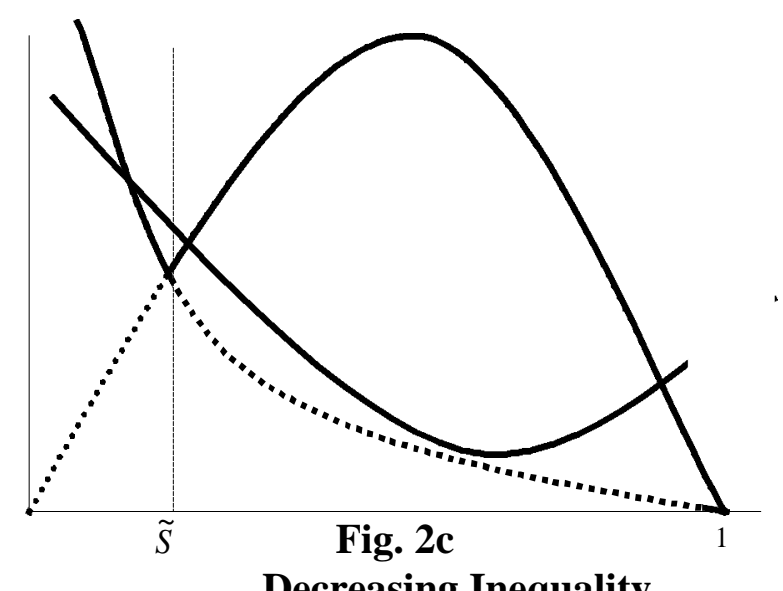

Decreasing Inequality

$\omega$

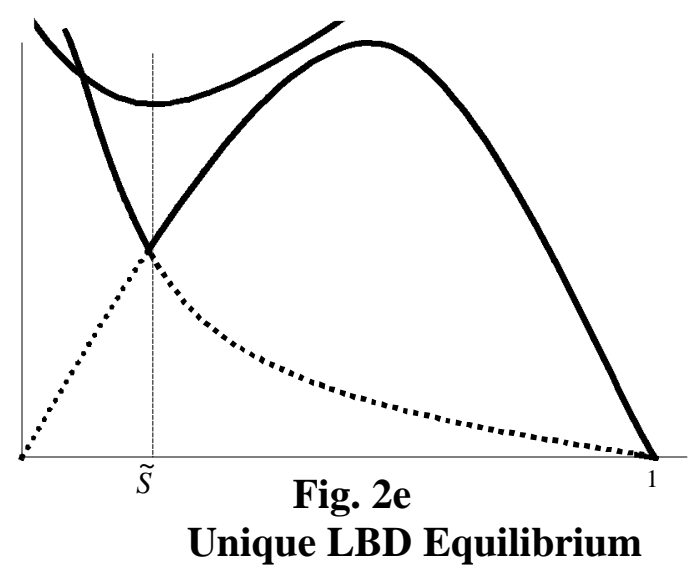

